\title{
THE ROLE OF SOCIAL WORK GENERAL PRACTICE IN HANDLING PARENTAL ABUSE OF CHILDREN: CONTENT ANALYSIS
}

\author{
Mahmoud Ali Mahmoud Radwan \\ Assoc. Prof. Dr., Department of Social Work Areas - Faculty of Social Work - Helwan University. \\ Department of Social Sciences - Faculty of Arts and Sciences - Qatar University, \\ mradwan@qu.edu.qa
}

\begin{abstract}
Childhood is considered to be one of the most important and most effective stages of growth during the human life. Some children suffer from problems and face difficulties as a result to various social and economic changes. The study observes problems facing families and communities highlighting child abuse as a key phenomenon. The study sheds light on a number of abuse forms like that of physical and verbal abuse and the ignoring technique applied by some parents. Aiming to determine the causes behind such abuse and the factors behind the problem at hand, and shedding light on the general practice of social work in dealing with it. The researcher uses the descriptive analytical method throughout the study and concludes that parental abuse may have various effects on children such as; psychological, social, educational, and health problems.
\end{abstract}

Keywords: abuse, social work, general practice

\section{THE PROBLEM OF THE STUDY}

The study is of importance due to the importance of childhood being one of the key factor in the society and due to the importance of the study in the present time and its added importance as today's children will be tomorrows leaders.

During childhood, personalities and values are formed thus it is vital for children to grow around a role model in-order to evolve and develop as such person may have a huge impact on their personality and in the way they perceive life. (Tawfiq, 1998, 79). Family is the initial environment which must meet the needs and requirements of the child nurturing him with care, love, compassion, psychological and social security. A family may also install cultural and traditional values qualifying him to become the responsible adult in the future, (Dakkak, 2004,169). Thus, the process of interaction between the child and his parents is clear in determining the criteria for the reward and punishment for the behavior of the child so he can gain in-depth social experiences of family life enablinh him to achieve social harmony (Al-Jumaili \& Abdo 2014, 73).

Children have multiple basic needs including what is psychological like their need for security, love and power, and what is physical such as the need for clothing, food, housing, and what is social such as 
educational, recreational, health care and the formation of traditions and values, and his outlook on life and meeting these needs through the care they provide to the child (Fahmi, 2000, 3). Making the family is the primary institution which bears meeting the psychological, social, mental and educational needs all together. If these needs are not fulfilled they will turn to problems and may later affect the child's personality and behavior. Thus, any unmet needs may cause a disability in the personality pattern of the child. And this is due to the strong interaction between offspring's with their families compared to anyone else in the community, (Abdullah, 2013, 179). Moreover, Children suffer a lot from problems and difficulties either as a result of their families or reasons related to society as a whole as a result of the multiple associated social and economic changes. Therefore, the study works on studying the emergence of new and changing problems facing families and communities, especially the phenomenon of child abuse.

Children are the biggest victims of abuse. Especially for children living in third world countries where many suffer from psychological abuse either from a member of their family, or a teacher at school, or an employer, or in the general public, (Naji, 1999, 44). Child abuse is therefore, becoming a global issue currently. In the United States of American (USA) a survey was conducted in 1995 and confirms that $5 \%$ of parents beat their children. In Great Britain, according to a report for the Ministry of Interior states that "four children are killed weekly by the hands of their parents." Moreover, the UNICEF stated in 2001 that two hundred children die annually due to parental abuse. Furthermore, The World Health Organization (WHO) has estimated that 40 million children less than 15 years of age suffer from abuse and neglectance. In India, It is reported that $36 \%$ of Indian mothers hit their children, $29 \%$ hold their children by their hair, and $28 \%$ beat their children with their hands. According to a survey conducted in Egypt, 37\% of children are being beaten by their parents, in addition to $26 \%$ of children abuse resulting in injuries such as fractures or permanent disability, (UNICEF, 2009).

Moreover, the problems of child abuse and the failure to meet children's physically and psychologically needs are not new to our area of expertise; they have been discussed over the years and have been witnessed in various societies. Although, attention towards child abuse is not new. The issue in hand is being of more importance today especially that researchers have been able to pinpoint the affects of the problem. However, today we aim to find solutions to end the ongoing children issue. It is currently understood that such as problem is widely addressed and witnessed as it is not limited to a certain group of people, but it is widely spread through-out the community; where it is in rich or poor classes, between education or uneducated parents, (Abdullah 2000, 90).

And due to social work as a humanitarian profession deals with individuals, groups and communities in light of scientific methods and technical skills through the primary and secondary specialized ways seeking to achieve complementary, therapeutic, preventive and developmental goals. Social work cooperates with a variety of disciplines to lead distinct roles on the human level (Gabal, 2001, 11). Where social work participates with other professions in providing the care for children and their families. It does so as a profession based on humanitarian philosophy that takes into account human dignity and stresses the need to achieve social and psychological adjustment of children and their families. Moreover, Social work also helps individuals and families in adapting and interacting within the society. Furthermore, Social work seeks for social justice and fights against all kinds of oppression and discrimination and contributes to solve and face societal problems aiming to develop the society and reaffirm the right of everyone to grow through the promotion of social integration and strengthen the links between education, technology and environment (Ali, 2012, 32). In the context of the great development which social work sciences saw, the concept of general practice appeared representing a theoretical and practical framework for social work programs (Solimon et al., 2005, 6). Thus, general practice in social work is a trend that is based on a theoretical basis including many scientific theories derived from the humanities, skillful foundations and values that reflect the distinctive nature of the practice of social work in multiple fields (Ali, 2013, 362). Thus, it is concerned with mutual relations through the content of the overall practice (practice areas) and institutions of Practice (primary social work - and multiple organizations) and social problems of a person in the environment (Habib, 2010, 20).

\section{THE IMPORTANCE OF THE STUDY}

The topic is of international interest especially that the topic in hand is perceived as a major step in the development of the community, aiming to ensure the improvement of children's position and find ways to protect their rights, as well as increasing child care. Paying unique attention to children in developing countries whom suffer from massive explosion of the population and represent a high proportion of members of the community and its component of human wealth that needs to be addressed and to be able to provide them with all means of care and wellbeing 


\section{THE OBJECTIVES OF THE STUDY}

The study aims to determine the causes, forms and the problems arising from parental abuse of the children and the role of general practice of social work.

\section{THE QUESTIONS OF THE STUDY}

1. What are the factors behind parental abuse?

2. What are the forms of parental abuse on children?

3. What are the problems arising from parental abuse on children?

4. What is the role of general practice of social work in dealing with parental abuse on children?

\section{TERMINOLOGY}

\section{a) The general practice in social work}

The appearance general practice in the social work is due to the first attempts to develop a unified concept of practice. It focuses on a holistic view with a focus on the parts that make up the whole to clarify the functional relationship between all the parts and the extent of interdependence (Ali, 2001.129).

It is defined as a style of one-catching practice that focuses on the perspective of relations and common borders. It emphasizes equally on the goals of social justice, formats of humanity and improving the standard of living and welfare (Al-Sanhouri, 2002, 462).

It is a kind of professional practice of social work that depends on the selection of some of the professional models and approaches available to specialists and their use in the professional intervention with the goal format according to the client format and layout problem (Habib, 2009, 27).

\section{b) Parental abuse of the children}

The word abuse means to do something wrong to someone or to say something bad or rude (Arabic Language Academy, 2004, 326)

In English (Abuse) means that a person misuses the right or authority or infringement on others. It is also to curse, abuse and insult with words (Studies \& Researches Office and 2004.20). Moreover, it is a deviation from the use of the right that results in harm to others. This harm requires responsibility (Saleh, 1999, 23).

In the social work, it means a repeated punishment, whether physically or psychologically through the deliberate beatings or physical uncontrolled punishment (Al-Sokkary, 2000, 21). In other words, an improper behavior that intends to cause a physical, psychological or economic harm to an individual or group. There are multiple types of abuse such as; physical, psychological or sexual abuse (Al-Dakhil, 2014, 9).

In this study, parental abuse means a direct abuse from a parent or both parents towards their own child. This abuse is represented in physical, or verbal abuse and/ or neglectance by a parent or both towards their child.

\section{TYPE OF STUDY}

The current study follows a descriptive and analytical research method.

\section{PREVIOUS STUDIES}

Karpetis (2010) presents a psychodynamic approach in his study of clinical social work practice with the father of a child who suffered from separation anxiety disorder symptoms. The theoretical background of the study is initially presented, followed by a description of the research setting and its participants. The clinician presents his work through critical incidents of parent and practitioner narratives during the assessment and intervention process. The effectiveness of the intervention with the father/parents and the resulting reduction in the child's symptoms appeared to be the consequence of the father's improvement in his role as both parent and husband, which in turn affected positively the mother's improvement in her parent and wife roles. Support to the father's adult part/strengths and the handling of the practitioner's counter-transference feelings were important parameters in evaluating the effectiveness of the intervention.

Based on Vered (2016) the study attempts to expand the knowledge base about neglectance by comparing the characteristics of children and parents involved in termination of parental rights proceedings in the Israeli legal system. Cases were classified as neglect $(72.7 \%)$, abuse $(19 \%)$ or non-child abuse or neglect (non- 
CAN; $8 \%$ ) and were compared on a range of variables. The results show that neglected children have the most developmental problems, and generally come from single-parent families, compared to abused children, who suffer the most mental health problems and come from 2-parent families. Finally, neglect is associated with the mother's history of drug abuse, and abuse is associated with the father's drug abuse and criminal record. In non-CAN cases, the courts criticize the Child Protective Service more than in neglect and abuse cases. Implications of the findings for social work practice as well as future research directions are discussed.

Moreover, Deiphine (2005) Cites a study on the role of depression and dissociation in the relationship between childhood sexual abuse and later parental functioning. Examination of parental behaviors; Assessment of mother's perception of the quality of the relationship with her child; Measurement of the history of abuse and neglect, depression and dissociation with the Childhood Trauma Questionnaire, the Diagnostic Interview Schedule Simplified and the Dissociative Experiences Scale; Use of the MaloweCrowne Social Desirability Scale to control for respondent bias; Results of dissociation.

Based on Hunt's study in 2016, the study analyses workers' experiences of supervision following interactions with hostile and intimidating parents. This analysis examines management and organizational responses to worker stress and assessed the adequacy of support that workers received. An online survey was designed to collect data on workers' experiences and free text responses were qualitatively analyzed for references to the supervision they received in response to working with parents. 590 participants responded to the survey. 402 were qualified social workers, and 423 worked in child protection. Participants had experienced a range of violent behavior from parents. The overwhelming theme in responses was the lack of support and supervision workers received, often in stressful and frightening circumstances. Approximately one quarter of participants only used organizational procedures, guidelines or protocols on dealing with hostile parents. Workers reported that mismanaged parental hostility affected their practice and the quality of protection that children received. The violence experienced had a significant negative impact on their personal and professional lives. Organizational responses in the form of supervision and education were often inadequate and resulted in children receiving reduced quality of protection. Recommendations for policy and practice change are discussed, with the aim of caring for workers and the children they protect.

Furthermore, Clément \& Chamberland (2009) investigated in their study the maternal attitudes towards corporal punishment and the attribution of blame towards the child on the basis of data gathering from a population survey of a representative sample of mothers and mother figures. A total of 3,148 women living at least half of the time with a child participated in a telephone survey. The independent variables included in the multivariate model predicting maternal attitudes and attributions include the child's, the mother's and the family's characteristics and social support. Results of the multiple regression analysis demonstrate the unique contribution of variables according to the mother's characteristics (mother's sensitivity to the consequences of violence, mother's experience of childhood violence and parental stress related to child's temperament). These results partially support the importance of prevention programs that would reduce stress and increase the level of parental empathy through the means of parental training.

Wolfe, (1993) studied child abuse interventions for two decades and has been plagued by poor definitions of what (or who) exactly is being treated, what constitutes 'success', and how services can be delivered in such a way as to minimize the harm to the child and to his/her family. Most recently, intervention/prevention programs reflect the growing recognition that child maltreatment is the product of the interaction between the Parent's abilities and resources and the child's emerging behavioral and emotional characteristics (i.e. the parent-child relationship), and place less emphasis on individual psychopathology. Accordingly, ways to strengthen this relationship offer considerably more promise than those aimed at correcting only one component (i.e. the parent) or treating only the visible symptoms of conflict. In an attempt to focus greater effort on prevention and early intervention, this paper reviews prominent risk factors that have been linked to physical abuse and neglect of children and their consequences. Major intervention targets are identified from this literature and discussed in reference to: (a) problems related to the family context; (b) child treatment needs; and (c) parent/caregiver treatment needs. The paper concludes with a discussion of promising developments in early intervention that are beginning to address problems in the early formation of the parent-child relationship (i.e. the pre-natal and infancy periods of development) and problems associated with parental competency and family support. Most notably, preventive efforts have been associated with more positive parenting knowledge, attitudes, skills, and behavior, as well as fewer child injuries, emergency room visits, and reports to protective agencies among at-risk parents and children. Further evaluation and expansion of these programs appears to be warranted by these data.

Based on Cheung's study in year 2014, it was stated that Parental abuse is supposedly objectionable because it is the instigation of the child's delinquency. Adding that this instigation is likely to stem from the 
impairment of parental control arising from parental abuse, with respect to social control theory. For the substantiation of this likelihood, the present study surveyed 229 users of youth social work services in Hong Kong, China. Results illuminate the mediating role of parental control for the instigation of delinquency and delinquent intention by parental abuse reported to happen at the age of 11 years. The results imply the importance of curbing parental abuse and enhancing or reviving parental control after parental abuse to prevent delinquent risks and expedite rehabilitation from the risks.

Byrne, (2012) study examines how the form of social support (informal or formal) and the time frame at which it is provided (at the start or end of the program) influence parental outcomes on the "Apoyo Personally Familiar" (APF) program for at-risk families showing inadequate child-rearing practices. A total of 496 parents participated, 247 parents referred by the municipal social services in the Autonomous Community of Castile and Leon (Spain), and 249 non-referred parents. Initial and final levels of use of and satisfaction with informal and formal support were used as predictors of change scores in self-rating measures of beliefs about child development, perceptions of the parental role and child-rearing practices, applying hierarchical linear regression analyses. Perceived use of and satisfaction with support explained around $22 \%$ to $49 \%$ of the change scores in the Nurturist belief as a simple view of child development, Couple agreement on educational matters, Permissive-neglectful practices and Coercion practices, after accounting for the variance due to risk status, financial situation and family structure variables. Informal support always has a positive impact irrespective of when the help is provided, whereas formal support only has a positive impact when applied at the start of the program. The adequate provision of social supports can be an efficient way to prevent child maltreatment by promoting changes in parental beliefs and practices related to at-risk parenting.

\section{RESULTS}

A. The study confirms that there are many reasons that lead to parental abuse against children. These reasons may vary; factors could range from low family income, the number of family members, low levels of education, and parental disorder.

B. Making the most common forms of parental abuse reflected in physical, verbal abuse and neglect.

C. Abuse against children may result in psychological, social, and educational problems. From the psychological problems are social; low self-esteem, anxiety, depression and stress. Moreover, withdrawal, violence and inability to establish reason are examples of social problems. As for the educational problems; weak academic achievement and underachievement are main examples of educational problems. Inability to mature properly and passing through unhealthy periods are examples of physical diseases in addition to the risk of mental diseases and their dealing with drugs.

D. Furthermore, The role of general practice of social work in dealing with parental abuse of children is represented in:

1. Assisting parents and children to recognize the problem, its nature and the causes of incompatibility between parents and children and helping them to identify the strengths and weaknesses they have and helping them to teach them how to deal with their problems.

2. Assisting parents and their children to improve their performance to their roles and helping them to identify the resources they already have or are existant in institutions of society that they can benefit from.

3. Finding a connection between the family and the institutions providing communication channels between parents and children. Such institutions play a key role in putting an end to the problem as such institutions know the nature of the existing needs of families and how to satisfy them.

4. Making adjustments in the institutions to be more responsive to the needs of individuals, where social work works with the foundation members to help them carry out their functions to the fullest.

5. Improving through the exchange of experiences between different institutions that work in the field of family care especially those specialized in dealing with abuse problems and establishing a base of information to facilitate identification of different needs and how to deal with them.

6. Assisting parents to determine their illogical ideas about education and also changing their behavior towards education.

7. Developing and improving social welfare policies. This would be the focus of the practice of social work at that level formats that people interact with. Here, the main role is planning and developing social welfare policies. 
8. Enabling both parents and children to help in performing their social roles and developing their abilities to solve and overcome daily problems. Providing a remedy for any defects in their abilities to perform their social functions as required. Pursuing to adjust with the environment they live in.

\section{REFERENCE LIST}

Abdullah 2000, Saleh: Children abuse, Cairo, Ain Shams University, Graduate Institute for Childhood, the Annual Scientific Conference.

Abdullah 2013, Magdi Ahmed: Mental disorders for children (symptoms - causes - treatment), Alexandria, University Knowledge Dar.

Al- Sanhouri 2002, Ahmed Mohamed: Advanced general practice in social work and the challenges of the $21^{\text {st }}$ century, Cairo, Al Arab Renaissance Dar.

Al-Dakhil 2014, Abdulaziz Abdullah: Glossary of Social Work Terms English - Arabic, Jordan, Dar of Curricula for Publication and Distribution.

Ali 2001, Maher Abo El-Maati: The general practice in social work in the field of youth welfare, Cairo, Zahraa East Library.

Ali 2012, Maher Abo El-Maati: New trends in International Social Work, Alexandria, Modern University Office.

Ali 2013, Maher Abo El-Maati: Introduction to Social Work with the teaching models and the profession practice in the Arab States, Cairo, Zahraa East Library, 2nd Floor.

Al-Jumaili \& Abdo 2014, Khairy Khalil, Badr Al-Din Kamal: Professional Practice in the field of family and childhood, Alexandria, Scientific Office for the Computer, Publishing and Distribution.

Al-Saleh 1999, Mosleh: Comprehensive Dictionary social science terms, Riyadh, Books World Dar.

Al-Sokkary 2000, Ahmed Shafiq: Social Work and Social Works Dictionary, Alexandria, University Knowledge Dar.

Arabic Language Academy 2004: Mediator Lexicon, Cairo, Sunrise International Library, 4th Floor.

Byrne ,2012\&other : Influence of form and timing of social support on Parental outcomes of a childmaltreatment prevention program, Children \& Youth Services Review. Dec2012, Vol. 34 Issue 12, p2495-2503.

Cheung ,2014 Chau-kiu: Delinquent risks of parental abuse at the age of 11 years among at-risk youth, Early Child Development \& Care. Oct2014, Vol. 184 Issue 9/10, p1458-1471.

Clément \& Chamberland ,2009: The Role of Parental Stress, Mother's Childhood Abuse and Perceived Consequences of Violence in Predicting Attitudes and Attribution in Favor of Corporal Punishment, Journal of Child \& Family Studies. Apr2009, Vol. 18 Issue 2, p163-171.

Dakkak 2004, Amal Hamdi: The media's role in protecting children from violence, the Arab Council for Childhood and Development, Childhood and Development Magazine, Issue 13, Volume 4.

Deiphine,2005, Collin-Vézina : The Role of Depression and Dissociation in the Link Between Childhood Sexual Abuse and Later Parental Practices, Journal of Trauma \& Dissociation. 2005, Vol. 6 Issue 1, p71-97.

Fahmy 2000, Mohamed Sayed: The tragedy of urban street children in the Third Millennium, Alexandria, Modern University Office.

Gabal 2001, Abdel-Nasser Awad Ahmed: Psycho-social work, Cairo, Egyptian Renaissance Library.

Habib 2010, Gamal Shehata: Modern issues, researches and trends in education and the practice of social work, Alexandria, Modern University Office.

Habib, 2009, Gamal Shehata: The general practice in the modern perspective of Social Work, Alexandria, Modern Collective Office.

Hunt \& other,2016: IF I FEEL LIKE THIS, HOW DOES THE CHILD FEEL?' CHILD PROTECTION WORKERS, SUPERVISION, MANAGEMENT AND ORGANISATIONAL RESPONSES TO PARENTAL VIOLENCE, Journal of Social Work Practice. Mar2016, Vol. 30 Issue 1, p5-24.

Karpetis 2010, George: Psychodynamic clinical social work practice with parents in child and adolescent mental health services: a case study on the role of the father, Journal of Social Work Practice. Jun2010, Vol. 24 Issue 2, p155-170.

Naji 1999, Please: Marginalized children's issues and rights, the Publications of Arab Center for Childhood and Development.

Soliman et al., 2005, Hussein Hassan: The general practice in social work with the individual and the family, Beirut, University Corporation for Studies, Publishing and Distribution.

Studies \& Research Office 2004: English - Arabic dictionary, Beirut, Scientific Books Dar.

Tawfiq 1998, Mohammad Najib: social work with families, children and the elderly, The First Book with Family, Cairo, Egyptian Anglo Library. 
UNICEF 2009, Report on the protection of children from violence, exploitation and abuse.

UNICEF, 2001: The children in the world in 2001 mode, Kuwait Association for the Advancement of Arab Children, Arab Children Magazine, Volume VII.

Vered,2016 Ben-David: A Focus on Neglect: Comparing the Characteristics of Children and Parents in Cases of Neglect, Abuse, and Non-CAN (Child Abuse and Neglect) in Israeli Rulings on Termination of Parental Rights, Journal of Aggression, Maltreatment \& Trauma. Aug2016, Vol. 25 Issue 7, p721740

Wolfe , 1993 David A : Child Abuse Prevention: Blending Research and Practice, Child Abuse Review. Sep 93, Vol. 2 Issue 3, p153-165. 